\title{
Identificación visual a partir de íconos
}

\author{
Sandra Rodríguez-Mondragón, Oscar Herrera-Alcántara, \\ Luis Jorge Soto-Walls, Manuel Martín Clavé-Almeida \\ Universidad Autónoma Metropolitana, \\ México \\ \{sandra.rgz.mondragon, luissotowalls, mclavealmeida\}@gmail.com, \\ oha@correo.azc.uam.mx
}

\begin{abstract}
Resumen. Esta investigación muestra parte del desarrollo de un modelo de proceso para identificación visual a partir de íconos. Dicho modelo brinda la posibilidad de trabajar con un banco de datos de más de 1500 imágenes de iconografía proveniente de indumentaria indígena de Chiapas, México, de forma eficiente. Lo que permite trasladar este lenguaje visual a diversos formatos digitales de imagen y así poder usar esta información visual en productos de diseño. Este desarrollo metodológico tiene como objeto contar con una herramienta para desarrollar un lenguaje visual de la cultura mexicana y obtener un modo de expresión visual propia a partir de ella con sus cualidades formales. La propuesta fue realizada con base en investigación documental y de campo, así como con múltiples métodos que van de lo cualitativo a lo cuantitativo para concluir en el análisis de datos visuales, que generan un alfabeto gráfico de expresión formal y de descripción visual; esto último con ayuda de un programa de cómputo basado en una máquina de pila, que permite generar de 2 a 16 imágenes de 100 a 5000 pixeles en tiempos de 60 a 180 segundos, lo que facilita el análisis de imágenes y la toma de decisiones para la selección de iconos y su implementación en el alfabeto gráfico antes citado. Como caso de estudio se trabajó con siete comunidades del estado de Chiapas de los grupos lingüísticos tzotzil y tzeltal a razón de ser grupos representativos en la producción de textiles e indumentaria indígena de México.
\end{abstract}

Palabras clave: lenguaje visual, identificación visual, grupos de simetría, icono.

\section{Visual Identification from Icons}

\begin{abstract}
This research shows part of the development of a process model for visual identification based on icons, this model provides the possibility of working with a database of more than 1500 images of iconography provided by ethnic clothing from Chiapas, Mexico, from efficient way. This allows us to translate this visual language into various digital image formats and thus be able to use this visual information in design products. This methodological development aims to have a tool to develop a visual language of Mexican culture and obtain a mode of visual expression of its own with its formal qualities. The proposal was made based on documentary and field research, as well as with
\end{abstract}


multiple methods ranging from the qualitative to the quantitative to conclude in the analysis of visual data, which generate a graphic alphabet of formal expression and visual description; this last with the help of a computer program based on a stack machine, which allows generating from 2 to 16 images of 100 to 5000 pixels in times of 60 to 120 seconds, which facilitates image analysis and decision making for the selection of icons and their implementation in the aforementioned graphic alphabet. As a case study, we worked with seven communities in the state of Chiapas of the Tzotzil and Tzeltal linguistic groups, as representative groups in the production of textiles and ethnic clothing from Mexico.

Keywords: visual language, visual identification, symmetry groups, icon.

\section{Análisis visual}

\subsection{Descripción del proceso}

El análisis visual se desarrolló con base en un proceso de identificación visual de íconos $^{1}$ en las muestras recopiladas en la investigación de campo, a continuación se presenta una muestra del resumen de íconos identificados en cuatro de las ocho comunidades visitadas, el análisis se reduce a razón del número de muestras obtenidas por comunidad (ver Tabla 1). Dentro del análisis visual en las muestras recopiladas (255 piezas), se identificaron al menos cinco íconos diferentes por huipil ${ }^{2}$, parte de esta investigación busca realizar desarrollos a partir de la iconografía identificada en el muestreo, de ello se propone realizar desarrollos de sistemas formales ${ }^{3}$ basados en los íconos, sin embargo realizar una cedula ${ }^{4}$ por ícono identificado implica hacer cinco cédulas en promedio por prenda, lo que en la totalidad del muestreo es de 1,275 cédulas, por lo anterior se propuso realizar estos desarrollos por medio de programación gráfica; así, trabajar las bases de datos del muestro en conjunto con la programación gráfica, permite realizar los desarrollos para nuevas propuestas formales. En el número de cédulas propuestas, además, se realizan cinco opciones de desarrollo aplicando variables independientes lo que deriva en 6,375 opciones y si a esto le agregamos variables dependientes las cifras son exponenciales, esta es la justificación del trabajo por medio de programación (ver Figura 1). Por otro lado, el análisis visual sólo implica la acción de identificar íconos, así la programación grafica funge como herramienta de desarrollo, y la identificación visual del caso de estudio se realiza aplicando el modelo

1 Para la palabra íconos, se adopta la definición como "imágenes, que contienen información o códigos que se necesitan decodificar [1]

2 Huipil: Es una prenda de mujer de origen prehispánico, que se produce aún en algunas regiones de México [2].

3 Referente a forma: Todo lo que pueda ser visto posee una forma que aporta la identificación principal en nuestra percepción [3].

4 En este documento se maneja el término "cédula" indicando un formato que incluye el registro de imágenes y datos escritos del producto analizado; esta información es la que alimenta la base de datos para el análisis de íconos. 
Tabla 1. Ejemplos de iconografía de grupos indígenas.

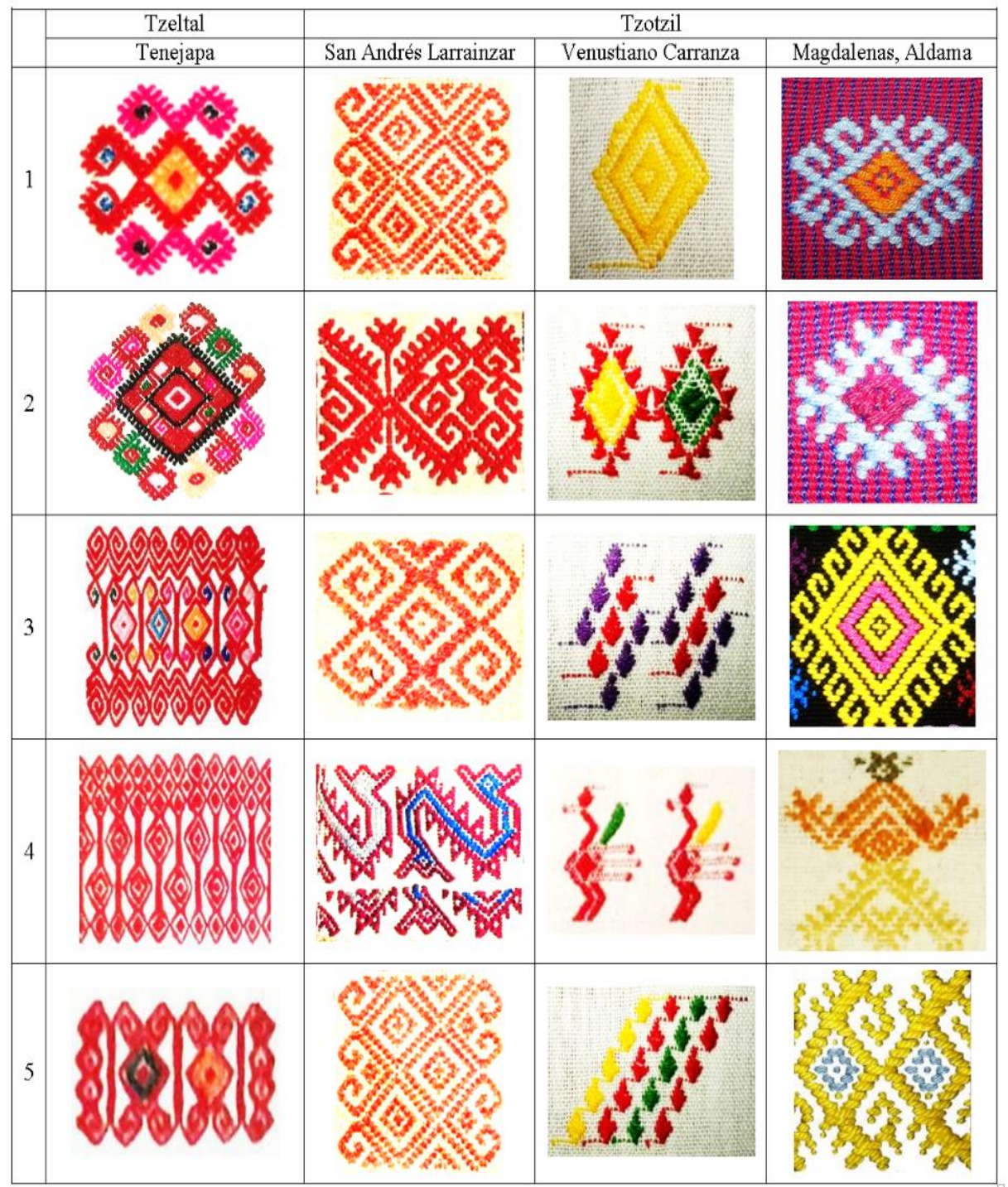

de propuesto en esta investigación. La identificación de íconos se hace de forma visual, con apoyo de programas de $\mathrm{CAD}^{5}$, y el uso de herramientas de parámetros básicos de manipulación de imágenes digitales tales como el brillo, las sombras, la saturación y contraste de color. Para el desarrollo del alfabeto requerido por el software se aplicó un criterio de análisis visual de la iconografía identificada, a partir de ejes de simetría o módulos primarios, en imágenes monocromáticas en blanco y negro.

5 CAD, “Computer Aided Design” (Diseño Asistido por Computadora) [2] 

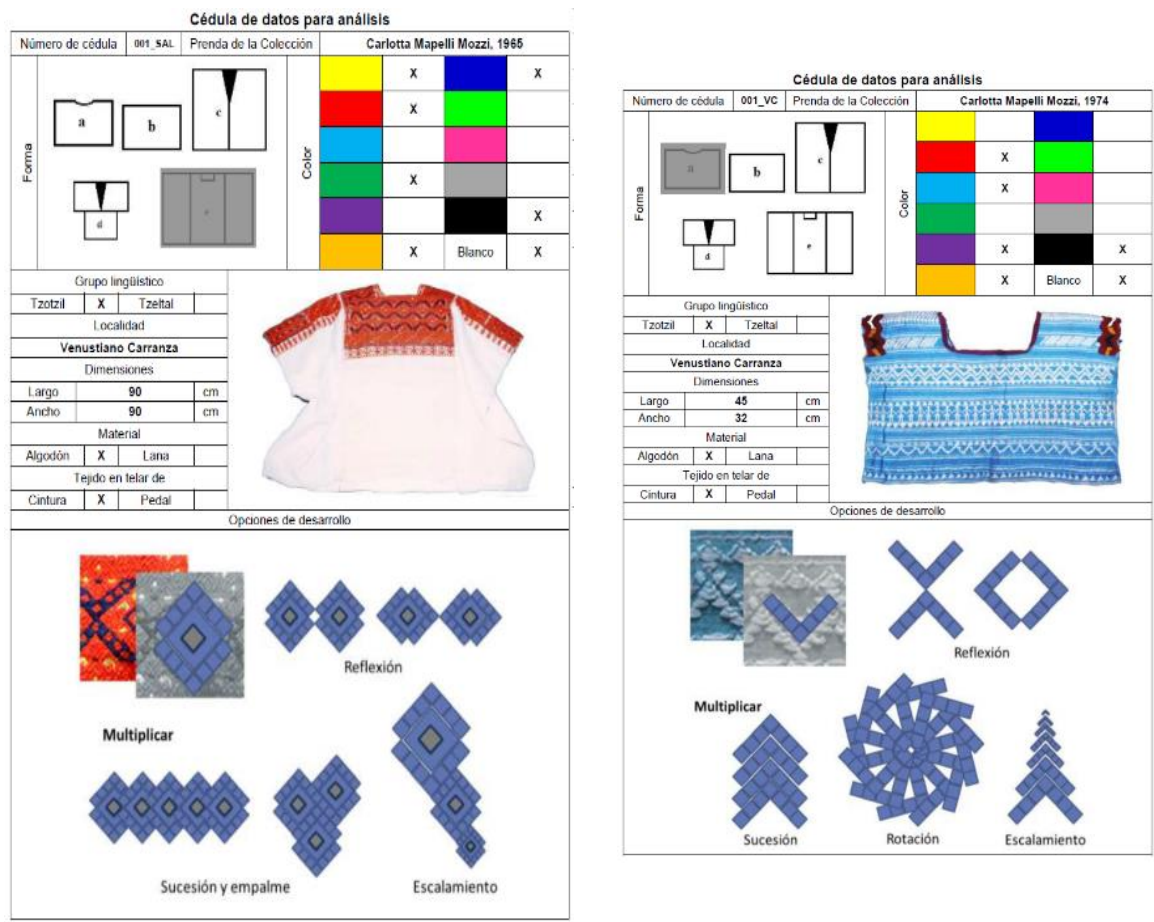

Fig. 1. Ejemplos de cédulas de análisis.

El análisis visual de íconos se realiza de forma manual, la descripción de este proceso consiste en cuatro etapas:

1. Identificación de iconografía en indumentaria indígena.

2. Digitalización de los íconos identificados.

3. Análisis geométrico visual a partir de isometrías (simetría, asimetría); abstracciones visuales.

4. Desarrollo de un alfabeto gráfico de lenguaje formal de descripción visual.

Sin embargo en este análisis visual, se presentan dos tipos de íconos: simétricos y asimétricos. Por lo que en análisis de íconos se desarrolla manualmente, llevando las entidades formales ${ }^{6}$ a su mínima expresión visual u óptica, siempre que permanezcan cualidades que mantenga su complejidad. Gracias a este análisis, se logra obtener la premisa de que hay entidades formales que son simétricas, pero que deben mantenerse como sistemas formales para preservar su identidad visual.

Por otro lado, con base en las entrevistas realizadas con expertos, se optó por trabajar el análisis de los íconos geométrico, debido a que la mayoría de los grupos trabajan formas de este tipo, una excepción es Zinacantán, sin embargo, en su huipil de boda si trabajan íconos geométricos (Tabla 2).

6 En este documento el concepto de "entidades formales" refiere a imágenes generadas a partir de los íconos, por lo tanto, tienen forma y dimensión y son identificadas por medio de la vista. 
Tabla 2. Especialistas entrevistados.

\begin{tabular}{cll}
\hline Nombre & Descripción \\
\hline 1 Brenda Ojinaga Zapata & Coordinadora de investigación del CTMM \\
\hline 2 María López Santíz & $\begin{array}{l}\text { Indígena de Oxchuc, Lic. en Lengua y cultura, } \\
\text { investigadora y guía de la sala textil del CTMM }\end{array}$ \\
\hline 3 Mariano Pérez Ruiz & $\begin{array}{l}\text { Director del museo de Culturas Populares, de San } \\
\text { Cristóbal de las Casas, Chiapas }\end{array}$ \\
\hline 4 Sergio Arturo Castro Martínez & $\begin{array}{l}\text { Ingeniero agrónomo, maestro, veterinario, poliglota y } \\
\text { coleccionista de textiles de Chiapas }\end{array}$ \\
\hline 5 & $\begin{array}{l}\text { Patricia Sánchez López } \\
\text { Cervantes }\end{array}$ & Directora del centro cultural y biblioteca Na Bolom \\
\hline 6 & Walter F. Morris Jr. & $\begin{array}{l}\text { Especialista en textiles indígenas de Chiapas, escritor e } \\
\text { investigador }\end{array}$ \\
\hline
\end{tabular}

\subsection{Desarrollo alfabeto gráfico de lenguaje formal de descripción visual}

Las abstracciones visuales o entidades formales del alfabeto gráfico, se trabajaron manualmente debido a que antes de hacer este análisis, la base de datos no contó con la solidez que permitiera identificarlas con inteligencia artificial. La proyección de esta investigación propone que se pueda realizar la predicción de las cadenas gráficas y generar el alfabeto visual por medio de inteligencia artificial. El análisis visual, se ejemplifica en tres casos donde se trabaja el análisis de íconos a partir de simetrías o asimetrías y abstracción visual (mínima expresión).

El análisis se desarrolló manualmente y en el programa de cómputo se desarrolló con base en este procedimiento, a partir de variables dependientes e independientes donde se aplican criterios de grupos de simetría [3].

Los grupos de simetría del plano, llamados también grupos cristalográficos, se caracterizan por contener dos traslaciones independientes, cuyas direcciones no son paralelas ni opuestas, pudiendo tener cualquier otra isometría. Hay que considerar la restricción cristalográfica, demostrada por Barlow, por la que las únicas rotaciones que pueden formar parte de un grupo de simetría del plano son las de orden 2, 3, 4 y 6, es decir, rotaciones de ángulo $180^{\circ}, 120^{\circ}, 90^{\circ}$ y $60^{\circ}$. Con esta restricción, sólo existen 17 grupos de simetría del plano (ver Figura 2) [3].

En este proyecto se propone desarrollar sistemas con mayor variación que en los grupos de simetría respecto a los ángulos de rotación $\left(180^{\circ}, 120^{\circ}, 90^{\circ}\right.$ y $\left.60^{\circ}\right)$, se propone dentro del software un controlador que permite al usuario modificar los grados manualmente en intervalos de 5\%, se propuso este valor porque a menor graduación se dificulta percibir visualmente la variación.

Para definir las traslaciones, se asignan valores numéricos a las posiciones de los íconos con base en la dimensión del módulo primario (alfabeto), así por ejemplo 1 es el valor dimensional del ícono y 2 es el doble de la dimensión del ícono; la forma de estructurar los valores para las cadenas generadoras de gráficos se realiza con base en los grupos de simetría. 


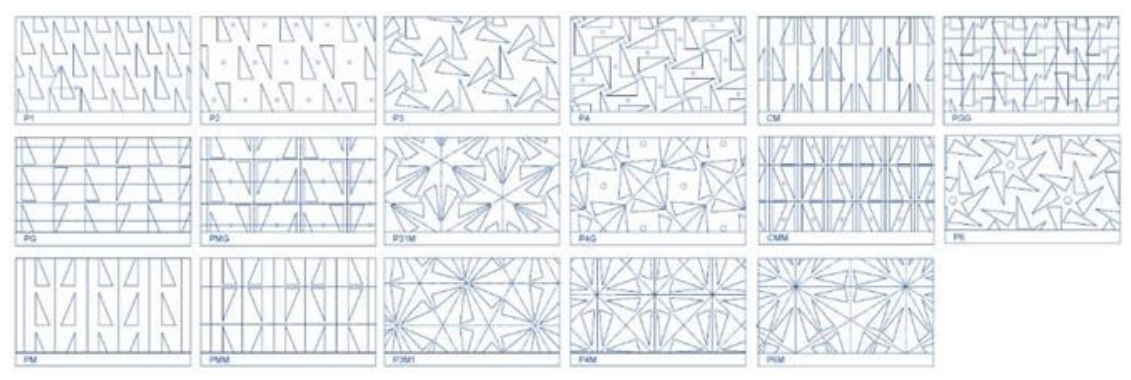

Fig. 2. Grupos de simetría del plano [4].
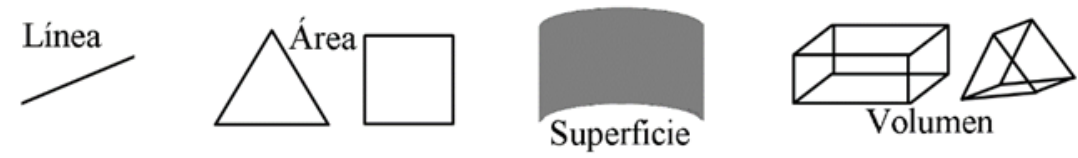

Fig. 3. Tipos básicos de elementos y superficie elemental [6].

Caso 1. Asimetría. Se identifica visualmente un ícono del huipil de Tenejapa, una cualidad de la iconografía de los grupos tzotzil y tzeltal, es el desarrollo de sistemas formales, así como se puedo ver anteriormente en la Tabla 1, las entidades formales son grupos de figuras simples, y dentro de una clasificación en lenguaje de diseño, se puede decir que los íconos son patrones formales.

En este caso, el ícono o patrón formal seleccionado, no presenta isometrías directas o indirectas, por ello se busca llevarlos a su mínima expresión visual, manteniendo sus cualidades formales, antes de que el nivel de abstracción sea tal, que se pueda confundir con formas básicas como líneas, puntos o incluso planos geométricos.

De esta forma se logra abstraer el ícono hasta conformar dos módulos que permiten desarrollar dos patrones, que a su vez en repetición conforman el ícono completo; este procedimiento brinda la posibilidad de programar el comportamiento de las formas con un nivel de complejidad 4, dónde se atribuye este valor al número de módulos primarios que en su conjunto estructuran el ícono analizado, más 2 que representa las primeras composiciones gráficas desarrolladas con los módulos (Tabla 3).

Así, se establece una escala de niveles de complejidad por número de módulos primarios más el número de módulos secundarios y queda comprobado en este análisis que ambos tienen cualidades formales que les permite mantener su identidad visual. Lo anterior desarrollado con base en el método de análisis de elementos finitos [5], ver Figura 3:

El método de análisis de elementos finitos, se basa en seccionar los sistemas en elementos con objeto de dividir un problema para resolverlo a partir de estos sub problemas. A cada uno de ellos lo conocemos como elementos y los principales son elementos básicos, tales como la línea, el área, el volumen y las superficies [5].

En este análisis se sigue el principio del modelado en sistemas CAD, por medio del método de elementos finitos, dónde se aplica la discretización del sistema, y ello se da por medio de sistemas simétricos; para llegar a esto, los sistemas CAD se basan en la 

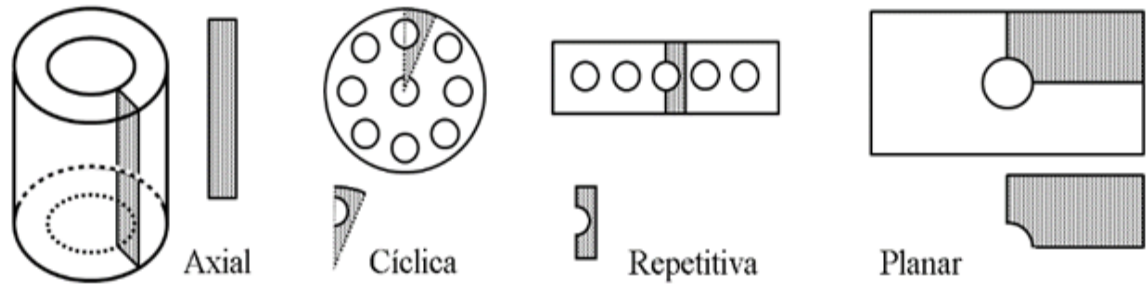

Fig. 4. Tipos de simetría [6].

geometría bidimensional y a partir de ella generan la tridimensionalidad. Así, los cuatro tipos de simetría que operan son: axial, planar, cíclica y repetitiva (ver Figura 4).

Caso 2. Simetrías. En este análisis sólo consiste en trabajar la visualización y realizar secciones en el ícono, contemplando que si se trabajan reflexiones en los ejes $\mathrm{X}$ y Y, se puede obtener a partir del módulo primario el sistema o ícono completo. Esto se desarrolla con simetría planar, es el análisis de menor complejidad, y se puede programar de cómo se trabajan las operaciones de algebra simple. Cabe mencionar que de los íconos analizados en este estudio, en ningún caso se identificaron módulos primarios después de realizar dos secciones; también podemos afirmar que en su mayoría sólo se logra realizar la primera sección, debido que la complejidad es parte de la identidad visual de un ícono y a mayor número de secciones ésta se pierde. Por otro lado, cuando los íconos tienen forma simple, como por ejemplo un rombo, y se dividen en más de una sección, la forma llega a ser tan abstracta que se confunde con expresiones formales básicas como líneas, triángulos o secciones. Por lo anterior, después de este análisis y con base en la frecuencia de los casos identificados de uno o dos ejes de simetría para lograr el módulo primario, se puede mantener como cualidad formal el número de ejes de simetría, dando por sentado que como máximo se debe trabajar con dos, para mantener la identidad visual del ícono (ver Tabla 4).

Caso 3. Mixto, simetría y asimetría. Del total de íconos analizados, se identificó un porcentaje del $50 \%$ que muestra cualidades formales para trabajarse a partir de ejes de simetría o abstracción en dos o más módulos primarios. Muestra de ellos es este caso, sin embargo, lo recomendable en un análisis formal de ese tipo es trabajar a partir de dos o más módulos primarios, idealmente dos; este tipo de desarrollos, es decir de asimetrías, tiene mayores posibilidades de mantener la identidad visual del caso de estudio, con excepciones formales que por complejidad, incluso a partir de un módulo primario mantienen su identidad visual. Este análisis, fundamentado en simetrías, asimetrías y mixto, es la base del desarrollo de software, dónde los diferentes módulos primarios identificados, constituyen el alfabeto gráfico formal. Es preciso, puntualizar que, el alfabeto gráfico, se debe realizar con base en un vasto muestreo que permite al investigador adquirir un acervo visual del caso de estudio (ver Tabla 5). Así, la identidad visual, se genera en este proceso de exploración visual y el análisis de simetrías se realiza de forma manual. 
Sandra Rodríguez-Mondragón, Oscar Herrera-Alcántara, Luis Jorge Soto-Walls, et al.

Tabla 3. Caso 1, ejemplo de asimetría [7].

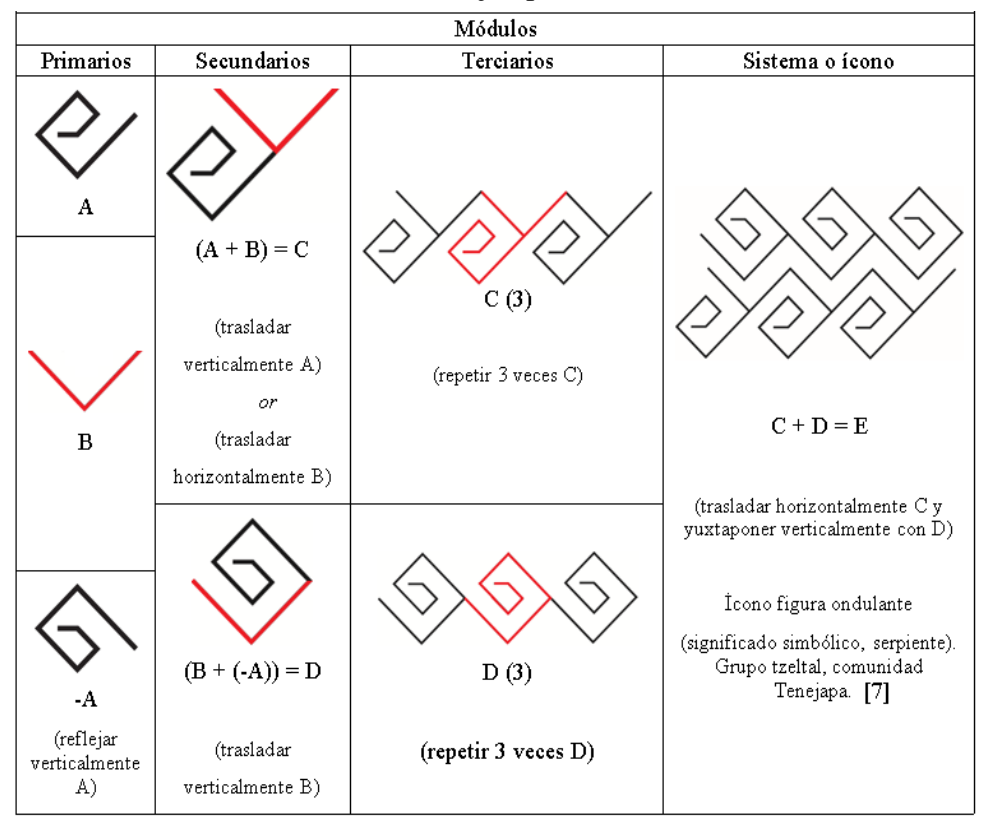

Tabla 4. Caso 2, ejemplo de simetría [7].

Modulo
Primario


Tabla 5. Caso 3, ejemplo Mixto, simetría y asimetría [7].

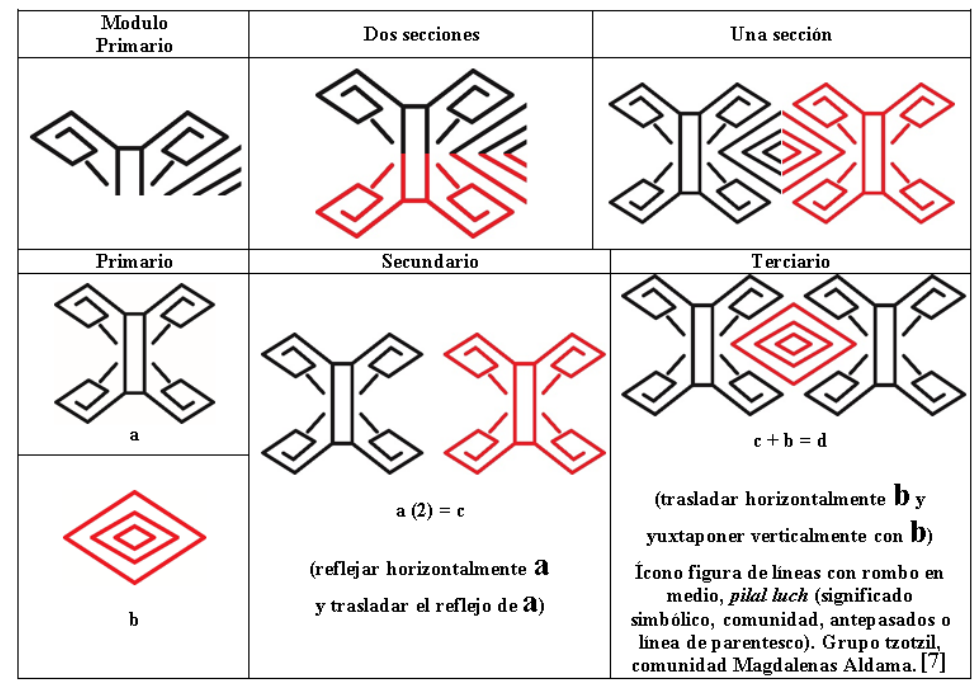

\subsection{Desarrollo conceptual del programa y análisis}

Para delimitar los operadores, se trabajó con una matriz de diseño aplicando a éstos la función de variables dependientes e independientes, así se logra experimentar de forma estructurada con las posibilidades de desarrollo de programación gráfica. A continuación se presenta el ejemplo de una matriz para el desarrollo conceptual de la herramienta computarizada, donde los controladores o variables independientes son los operadores (sistemas de simetría) y las variables dependientes son los valores numéricos que se asignen de forma fija o por medio de una ecuación. Así, en este ejemplo se presentan dos formas de simetría que son las únicas variables independientes; por otro lado, el porcentaje de escalamiento, el número de módulos o repeticiones de un ícono y las operaciones matemáticas o ecuaciones son variables dependientes que operan en la interface gráfica de forma manual por el usuario, en este caso se proponen las funciones trigonométricas de seno y coseno para colocar los íconos en el espacio de trabajo (el plano XY). Con este universo de dos variables independientes y tres variables dependientes a partir de un solo ícono se pueden lograr un sinnúmero de combinaciones; dentro del análisis visual la única variable que muestra restricciones de operatividad es el escalamiento, debido a que de acuerdo con la forma del ícono que se trabajé éste puede ser limitado a permitir un mínimo de $50 \%$ y con base en percepción de visual de la forma también el porcentaje superior a $100 \%$ puede estar limitado al plano en que se reproduzcan las imágenes (ver Tabla 6).

A continuación, se presentan algunos ejemplos de lo que se puede obtener con base en la matriz anterior (Tabla 7).

En los ejemplos A, B y C, se aplica la función seno al comportamiento del ícono seleccionado y la variable del número de íconos es 10; en estos ejemplos, la operación es la misma y se modifica la sección del ícono, ellos demuestra que además en la 
Tabla 8. Ejemplo de cadenas de gráfica (traslación y reflexión). Sandra Rodríguez-Mondragón, Oscar Herrera-Alcántara, Luis Jorge Soto-Walls, et al.

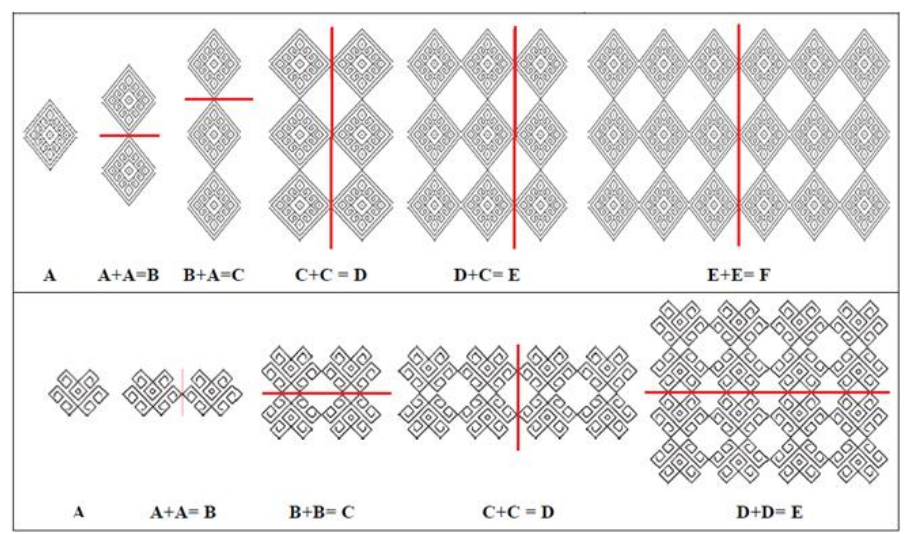

memoria del programa se pueden almacenar las secciones de íconos como opciones de desarrollo formal; en lo que respecta al espaciado entre íconos, este obedece a la magnitud real del ícono seleccionado, es decir, uno, por lo que en dichos ejemplos los ícono es la cresta de la gráfica aparecen unidos, visualmente hablando, porque solo están uno después del otro. Por otro lado, en los ejemplos D y E, se trabajan simetrías, traslaciones y escalamiento a partir de un sólo ícono y los resultados muestran que se pueden desarrollar muchas variables formales, donde se mantiene la identidad visual.

Así, sí en la programación se desarrollan formas intermedias antes de llegar a la forma final, estas también conservan la identidad visual, debido a que se desarrollan con base en los módulos primarios almacenados en la base de datos, además incrementan el acervo de gráficas del software, por lo que el número de pasos que generan una gráfica es el directamente proporcional al número de sub sistemas que se generan en la trayectoria de una cadena de generación de grafica (ver cuadro 8). Parte de la importancia de almacenar estos sub sistemas es robustecer la base de datos, a fin de que por medio de programación esta información permita que el programa inferir desarrollos, es decir operaciones autómatas y principio de propuestas desarrolladas por medio de inteligencia artificial y conocimiento visual de los pueblos indígenas del caso de estudio.

\subsection{Desarrollo de prototipos iconográficos (CAD)}

Para desarrollar modelos CAD a partir de la iconografía identificada, se propone el siguiente proceso de cuatro pasos que se esquematiza a continuación y se describe posteriormente (ver Figura 5):

Seleccionar el o los íconos a desarrollar, se puede trabajar con entidades formales (letras) del alfabeto grafico visual desarrollado, o con íconos identificados en los grupos analizados. Hay dos posibilidades para generar propuestas, estas son: a partir de una sola entidad formal o de dos o más. Esta etapa del proceso implica ya diversidad y complejidad formal, pese a trabajar con un solo ícono, aunque éste sea parte del alfabeto formal, así una entidad formal es llevada a su mínima expresión visual (ver Tabla 9).

Trabajar con reflexiones tanto horizontales, en el eje X, como verticales, en el eje Y. Se puede trabajar con ambas o sólo una. Aquí, se inicia la conformación de patrones de desarrollo, que se dan al agrupar dos o más íconos: 


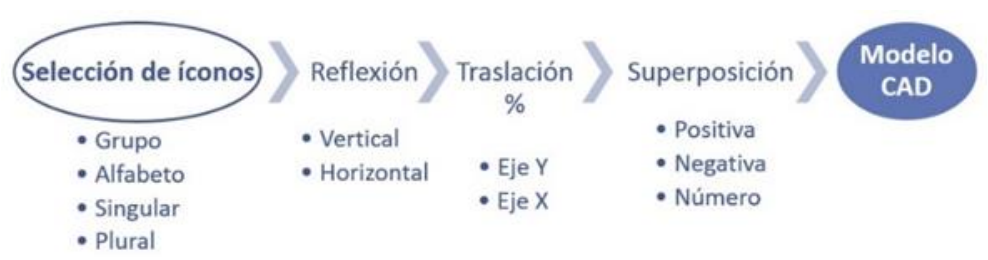

Fig. 5. Modelo para desarrollo de propuestas CAD.

Tabla 9. Selección de íconos.

\begin{tabular}{|l|l|l|}
\hline $\begin{array}{c}\text { Entidad formal o icono } \\
\text { del alfabeto }\end{array}$ & Icono completo & Desarrollos unitarios \\
\hline
\end{tabular}

Tabla 10. Tipos de superposición.

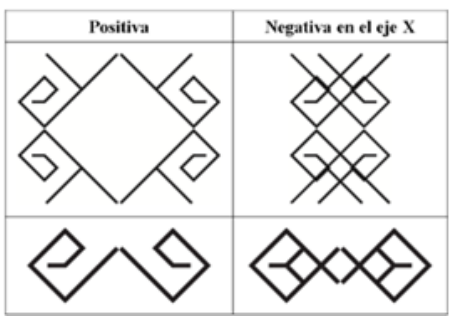

Tabla 11. Ejemplos de desarrollo CAD.

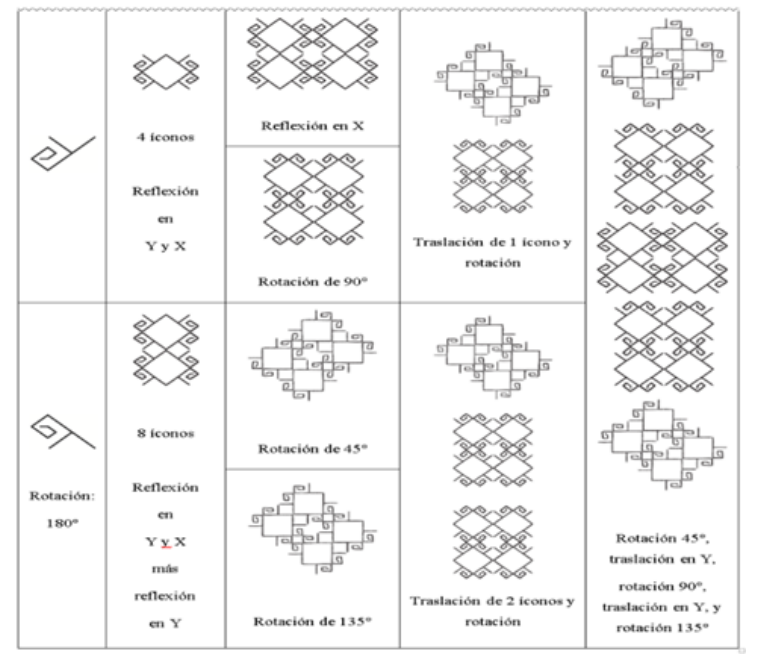


- Traslación, esta variable refiere a la posición del ícono en el plano bidimensional, las traslaciones pueden ocurrir tanto en el eje X como en el eje Y; operan con respecto a la dimensión del ícono, por ello se propuso manipularla con un factor porcentual, así en las cadenas de desarrollo gráfico A, x, 1, significa que hay un espacio del tamaño del ícono en el eje X.

- Como variable de superposición positiva o negativa, se aplica el término negativa cuando los íconos ocupan el espacio virtual de otro ícono y se mezclan con la entidad formal; y positiva cunado la superposición no invade la forma de otro ícono. Este parámetro está definido también en los ejes X y Y (ver Tabla 10).

Aquí se muestran sólo unos ejemplos de este proceso (ver Tabla 11), el total de propuestas desarrolladas fue de 1,581 y todo se realizó por medio de máquina de pila, por lo que existen módulos, patrones y sistemas gráficos, almacenados en dicha base de datos.

\section{Modelo de proceso}

A continuación se presenta el Modelo de proceso para identificación visual, a partir de íconos, mismo que está basado en la experimentación realizada por medio de análisis formal y propuestas gráficas desarrolladas con una aplicación computarizada. De acuerdo con Brunnello y Rocha: un modelo es una representación de una realidad compleja. Modelar es desarrollar una descripción lo más exacta posible de un sistema y de las actividades llevadas a cabo en él. Cuando un proceso es modelado, con ayuda de una representación gráfica (diagrama de proceso), pueden apreciarse con facilidad las interrelaciones existentes entre distintas actividades, analizar cada actividad, definir los puntos de contacto con otros procesos, así como identificar los subprocesos comprendidos. Al mismo tiempo, los problemas existentes pueden ponerse de manifiesto claramente dando la oportunidad para iniciar acciones de mejora [8].

El modelo consta de cuatro etapas (ver Figura 6):

1. Identificación o selección del caso; el proceso de identificación del caso de estudio, en esta investigación, está basado en el modelo de García-Córdoba [9], sin embargo este proceso se puede desarrollar por medio de cualquier modelo metodológico.

2. El análisis visual, donde se realiza la identificación de íconos consiste en:

- Digitalizar las imágenes, que en este modelo se realizó por medio de imágenes vectorizadas por cuestiones de calidad y con objeto de generar gráficos en cualquier formato posteriormente.

- Identifican de cualidades formales de los gráficos, bajo el criterio de su comportamiento ante el escalamiento y la rotación; y los efectos visuales cuando se modelan patrones o grupos de íconos, aplicando escalamiento y/o rotación.

- Análisis geométrico, a partir de isometrías en los ejes X y Y.

- Simultáneo al análisis geométrico, se desarrolla el alfabeto gráfico de descripción visual, éste se realiza a base de téselar los íconos en los ejes de simetría X y Y, hasta llegar a su mínima expresión gráfica, sin comprometer sus 


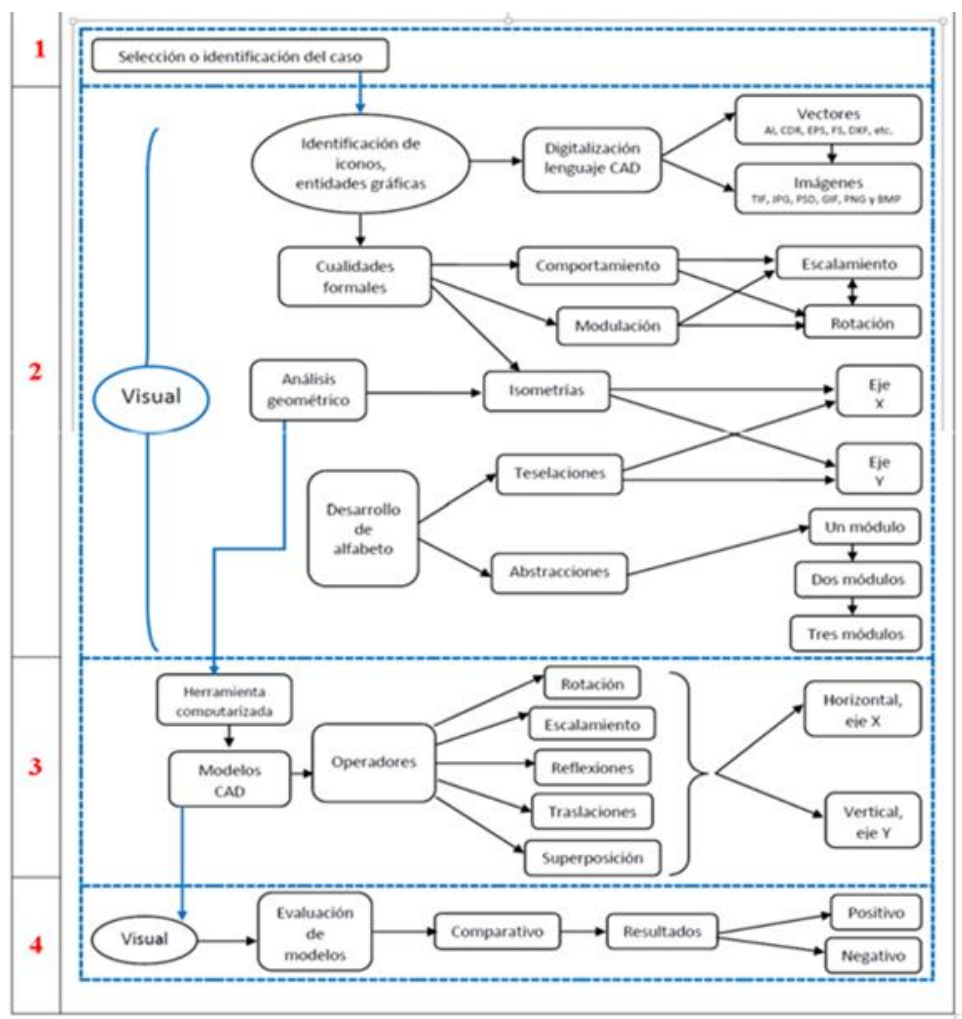

Fig. 6. Modelo de proceso para identificación visual, a partir de íconos.

partes; y abstracciones visuales, que permitan mantener la identidad gráfica de los íconos, estas abstracciones, idealmente consisten en identificar de uno a tres módulos primarios como máximo. En este proceso se busca que las abstracciones visuales cuenten con cualidades formales que permitan su identificación, evitando confundirlas con objetos geométricos comunes, tales como rombos, rectángulos, cuadrados, triángulos o secciones de ellos que fácilmente se pueden confundir con figuras geométricas regulares.

3. La experimentación visual, se desarrolla con la herramienta computarizada, que se desarrolló para este modelo. Dicha herramienta cuenta con cinco operadores o variables independientes: rotación, escalamiento, reflexiones, traslaciones y superposiciones, y éstas trabajan en función del eje $\mathbf{X}$ u horizontal y $\mathbf{Y}$ o vertical, que operan como variables dependientes; cabe aclarar que el alfabeto gráfico de descripción visual es el banco de datos de esta herramienta sumado a los sistemas de simetría.

4. Y finalmente, la evaluación de los resultados del modelo, que también se realiza a partir de visualización comparativa y se apoya en los modelos generados con la herramienta computarizada. 


\section{Conclusiones}

Para realizar la identificación visual a partir de íconos, es necesario desarrollar un lenguaje de descripción visual, que en este caso fue al alfabeto gráfico. Es posible realizar la identificación visual a partir de íconos, siempre que se cuente con una herramienta computarizada para la generación de gráficas. La identificación visual a partir de íconos, requiere de un banco de datos gráficos previo, para almacenar información en el programa de cómputo. La generación de posibilidades de desarrollo CAD con icnografía del caso de estudio, tiene un potencial de desarrollo ilimitado. En esta investigación, fue de gran importancia, operar de manera estructurada y precisa a fin de lograr delimitar el campo de desarrollo del caso de estudio, puesto que, por sus cualidades y diversidad estética, muestra un amplio potencial de desarrollo visual.

Los parámetros trabajados en las propuestas visuales, fueron limitados con el fin de contener la base de datos a modo de poderla manipular de forma eficiente. Se comprobó, que la herramienta computarizada, tiene la capacidad de procesar gráficos desde 100x100 hasta 5000x5000 pixeles de forma eficiente, es decir la generación de gráficos en un rango de tiempo que va de 5 a 180 segundos por imagen, dependiendo de su complejidad. Se pudo demostrar que sólo trabajando sistemas de simetría la generación de propuestas visuales es infinita.

Las abstracciones visuales, son una herramienta fundamental en la generación de propuestas visuales innovadoras, que mantienen la identidad visual del caso de estudio. Se pudo comprobar que el lenguaje visual ${ }^{7}$ del caso de estudio, tiene cualidades formales con amplio potencial de desarrollo estético, aun cuando se trabajen propuestas monocromáticas, en este caso sólo en blanco y negro. Traducir la gráfica textil a lenguaje computarizado, es una forma de preservación de la cultura de los grupos indígenas analizados. Ahora que se cuenta con el banco de datos visuales (6,375 imágenes), se puede continuar con el desarrollo del programa de cómputo e implementar las cadenas gráficas identificadas (60 cadenas en 1,275 íconos) a fin de predecirlas por medio de inteligencia artifical, ello brinda la posiblidad de realizar esta "Identificación visual a partir de íconos" de igual manera.

\section{Referencias}

1. Freund, R.: Tzotziles y Tzeltales, http://www.cdi.gob.mx/print.php?id_seccion=357 (2005)

2. Rodríguez, S.: Modelo de proceso para identificación visual a partir de íconos. Tesis doctoral. UAM Azcapotzalco, pp. 29-91 (2018)

3. Wong, W.: Fundamentos del diseño bi- y tri-dimensonal, Gustavo Gili, pp. 11-13 (1991)

4. Valor, M.: Diseño de herramientas gráficas para la catalogación de revestimientos cerámicos. Aplicaciones en el entorno del diseño gráfico. Tesis doctoral. Universidad Politécnica de Valencia, p. 432 (2007)

7 Se adoptó en esta investigación el concepto de lenguaje visual, al conjunto de íconos que constituyen una serie de imágenes producto del análisis realizado en esta investigación. 
5. Alawadhi, E.: Finite element simulations using ANSYS®. CRC Press, pp. 72 (2010)

6. Rodríguez, S.: Sistema Modular para la conformación de escultura cerámica monumental. Tesis de maestría. UAM Azcapotzalco, p. 94 (2014)

7. Morris, W.: Guía textil de los Altos de Chiapas. San Cristóbal las Casas, Chiapas, México: Thrums/Na Bolom, pp. 152 (2011)

8. Brunnello, M., Rocha, M.: Modelado de Procesos, en http://economicas.eco.unc.edu.ar/archivos/_2/U3-ModProc-11.pdf (2017)

9. García-Córdoba, F., García-Córdoba, L.: La problematización México. Cuadernos ISCEEM, p. 61 (1998) 